Revista Destaques Acadêmicos, Lajeado, v. 13, n. 1, 2021. ISSN 2176-3070

DOI: http://dx.doi.org/10.22410/issn.2176-3070.v13i1a2021.2830

http://www.univates.br/revistas

\title{
QUALIDADE DE VIDA NO TRABALHO SOB A LUZ DO MODELO DE WALTON
}

\author{
Jessyka Garcia Siqueira ${ }^{1}$, Claudia Lehnemann Tannhauser ${ }^{2}$, \\ Uiliam Hahn Biegelmeyer ${ }^{3}$, Maria Emília Camargo ${ }^{4}$, Munique Rech" \\ Danielle Nunes Pozzo ${ }^{6}$, Tânia Craco ${ }^{7}$
}

Resumo: Este estudo tem como principal objetivo analisar a Qualidade de Vida no Trabalho (QVT) dos colaboradores de um estabelecimento no qual está instalada uma pet shop e clínica veterinária, a partir do modelo de QVT de Walton. Para tanto, a pesquisa foi realizada através da abordagem descritiva-exploratória, que buscou identificar entre as oito dimensões propostas por Walton (1973) o nível de satisfação, quais os fatores de maior relevância, além de propor ações que melhorem a QVT dos funcionários, se necessário.Para a coleta de dados, o instrumento utilizado foi um questionário estruturado, que permitiu a análise quanti-qualitativa. Os resultados mostraram que os colaboradores, em geral, manifestaram estar satisfeitos com sua Qualidade de Vida no Trabalho, tendo sido identificados pontos de oportunidade, que tiveram ações sugeridas a fim de melhorar o índice de satisfação nas variáveis em questão.

Palavras-chave: Qualidade de Vida no Trabalho. Satisfação dos colaboradores. Modelo de QVT de Walton.

1 Bacharel em Administração, Pontifícia Universidade Católica do Rio Grande do Sul - PUCRS.

2 Doutora em Ciências da Saúde, Pontifícia Universidade Católica do Rio Grande do Sul - PUCRS.

3 Doutor em Administração, Universidade de Caxias do Sul - UCS.

4 Doutora em Engenharia de Produção, Universidade Federal de Sergipe - UFS.

5 Mestre em Administração, Universidade de Caxias do Sul - UCS.

6 Doutora em Administração, Universidad de La costa - Unicosta Colombia.

7 Doutora em Administração, Instituto Federal de Educação, Ciência e Tecnologia Sulriograndense. 


\section{INTRODUÇÃO}

A Qualidade de Vida no Trabalho (QVT) tem sido discutida desde a década de 1950, quando o funcionário ao ingressar em uma organização torna-se uma parte integradora e participativa, com necessidades a serem consideradas e sanadas, ao mesmo tempo em que o trabalho passa a ser percebido como agente motivador de insatisfação, ao invés de ser apenas um meio para suprir necessidades básicas (MARQUES, 2014).Porém, a expressãoQualidade de Vida no Trabalho foi cunhada apenas na década de 1970, devido ao receio existente em relação à competitividade e sucesso de técnicas gerenciais de QVT em outras empresas (MASSOLLA; CALDERARI, 2011; SAUER; RODRIGUEZ, 2014). No que tange a contextualização da QVT, o tema tornou-se mais relevante com o passar dos anos, devido às reivindicações dos trabalhadores quanto o conforto e satisfação no ambiente laboral e a consideração das companhias aos impactos na produtividade (CHIAVENATO, 2004).

Observam-se duas posições opostas na QVT: a reivindicação dos colaboradores quanto ao bem-estar e prazer no trabalho e o interesse das organizações quanto as potenciais consequências sobre a produtividade e a qualidade (CHIAVENATO, 2010). Por isso, é necessário que as empresas ofereçam qualidade de vida aos seus empregados, bem como salienta Vargas (2010) reconhecendo-os como seres humanos, com necessidades de ordem fisiológica e psíquica a serem sanadas, pois estes tendem a passar maior parte de tempo dentro dela. O nível de satisfação ou a falta desta no ambiente de trabalho,tratada na QVT, ganha notoriedade e se consolida como prática importante para a conquista das metas e aumento de rentabilidade no mercado que se está inserido, através do trabalho exercido pelos funcionários (PINHEIRO, 2012).

Neste panorama, este estudo dedica-se a analisar a QVTem um estabelecimento onde está instalada umapet shop e clínica veterinária, que será tratada por'X Pet Shop e Veterinária', para fins de sigilo que resguardam os dados desta empresa. O objetivo geral é analisar a Qualidade de Vida no Trabalho dos colaboradores daX Pet Shop e Veterinária a partir das dimensões de Walton. Também espera-se identificaro nível de satisfação dos funcionários em relação à sua Qualidade de Vida no Trabalho; identificar os fatores de Qualidade de Vida no Trabalho de maior relevância na percepção dos colaboradores; e propor ações que objetivem a melhoria das práticas de QVT.

O sucesso das práticas de QVT, como instrumento de gestão, não é determinada somente pelas características individuais ou situacionais de cada pessoa ou ambiente, mas sim pela atuação sistêmica destas (JIMENEZ, 2014). Assim sendo, a relevância deste estudo se verifica nas contribuições que ele poderá agregar à empresa e aos funcionários, pois se presume que ao se constatar o nível de satisfação dos colaboradores com relação ao trabalho, através da opinião dos próprios indivíduos, se viabilizam melhorias no 
ambiente organizacional, que acarretaram em benefícios para empregador e empregador.

\section{REFERENCIAL TEÓRICO}

As pessoas, no âmbito individual, possuem diferentes motivaçõese objetivos, quando se trata de suas carreiras e a satisfação é resultado do atendimento destes, um funcionário que tem suas necessidades satisfeitas tende a produzir mais e melhor (RAGAZINI, 2011). O tema qualidade de vida no trabalhoé assunto discutido desde os anos de 1950, durante o surgimento da abordagem sociotécnica e ganhou força organizacionalmente na década seguinte, quando empresários, sindicatos e cientistas sociais perceberam que a aplicação da qualidade de vida no ambiente corporativo impactava diretamente no rendimento, bem-estar e eficácia do trabalho dos funcionários (MARQUES, 2014).Na década de 1970, surge um movimento pela qualidade de vida no trabalho, principalmente nos EUA, devido à importância atribuída à competitividade internacional aliado ao sucesso dos estilos e técnicas gerenciais dos programas de produtividade japonesa (MASSOLLA; CALDERARI,2011)

A qualidade de vida no trabalho envolve fatores como pessoas, trabalho e organizações, onde se destacam a preocupação com o bem-estar do empregado e com a eficácia organizacional, além da participação dos funcionários nas decisões e relativas ao trabalho (MORETTI, 2007).É possível conceituar QVT como uma ferramenta de gestão com foco nos funcionários, cujo objetivo é o fornecimento de um ambiente adequado ao perfil do grupo de colaboradores e a estimulação do desempenho de suas atividades (JIMENEZ, 2014). As empresas passam por mudanças culturais, e passam a perceber a importância dos seus colaboradores (COGO, 2013; SANTOS; 2014).

Jimenez (2014) ressalta que os programas de QVT consistem em atuar considerando três potencialidades, sendo elas, biológicas, psicológicas e de cunho social, tornando-se de extrema necessidade práticas de QVT que possam lidar com a complexidade do ser humano.A gestão da Qualidade de Vida no Trabalho é um mecanismo importante para as organizações, pois por meio destes programas se consegue atingir os melhores resultados (SILVA; LIMA, 2011).

Não há como abordar o tema Qualidade de Vida no Trabalho sem mencionar a motivação e a satisfação das necessidades dos funcionários, como fatores essenciais para a QVT. A motivação é um motivo que leva à ação, explicando ocomportamento humano, onde relacionam-se as necessidades, satisfação e (MOREIRA, 2012). Quando as pessoas não estão motivadas a fazer algo ou atingir uma meta, é possível convencê-las do contrário, não obstante se estes indivíduos não estiverem dispostos a assumir tais atitudes e valores, o comportamento não será permanente e, logo, a insatisfação se fará presente novamente (MORETTI, 2007). 
O grau de dificuldade no ato de motivar levou ao surgimento de teorias, como a Teoria das necessidades de Maslow, embasada na hierarquização das necessidades humanas; a Teoria X e Y de McGregor que trata de dois perfis de comportamento dos empregados, em que as necessidades estão na satisfação com o trabalho; e a teoria motivacional de Hezberg, que relata que os fatores que influenciam a satisfação são diferentes daqueles que provocam a insatisfação.

No que se refere à motivação nas empresas, existem alguns sistemas motivacionais, que podem ser compreendidos como todos os incentivos que o indivíduo recebe para atingir determinada meta (MIRANDA, 2009). Estes incentivos motivacionais podem ser classificados como a remuneração e os benefícios sociais, as condições físicas ofertadas e psicológicas do trabalho e a segurança no posto laboral.Conhecer o que realmente motiva as pessoas é fundamental para o sucesso de qualquer organização.

Observa-se na literatura ao longo das últimas décadas que o tema QVT tem sido abordado sob diversos ângulos, sendo influenciado por fatores organizacionais e sociais vigentes ao período da realização do estudo. Inúmeros modelos têm sido desenvolvidos com o objetivo de identificar os aspectos que influenciam na Qualidade de Vida no Trabalho, conforme evidenciam Freitas e Souza (2009). Alguns dos modelos mais reconhecidos cientificamente são: os modelos de Walton (1973), Hackman e Oldham (1974), Westley (1979), Werther e Davis (1983) e Nadler e Lawler (1983). Para situações intrínsecas a um estabelecido tipo de trabalho, determinadas dimensões podem ser inseridas a fim de constituir um modelo mais pertinente (FREITAS; SOUZA, 2009). Neste estudo, optou-se pelo modelo de Walton (1973).

\subsection{O Modelo de Walton}

Walton é o primeiro autor norte-americano que dá início a uma linha de pesquisa de satisfação em qualidade de vida no trabalho, explicitando critérios sob a ótica organizacional (LIMONGI-FRANÇA, 2012). Ele dispõe da ideia que a QVT é representada na humanização do trabalho e na responsabilidade social, envolvendo o atendimento das necessidades e aspirações do indivíduo pela reestruturação do desenho de cargos e novas formas de organizar o trabalho, aliado à formação de equipes de trabalho com um poder de autonomia e melhoria do ambiente organizacional (SANTOS, 2012).

$\mathrm{O}$ modelo de Walton sugere oito categorias que enfatizam os fatores de influência na QVT, sendo eles: compensação justa e adequada, condições de trabalho, uso das capacidades, oportunidades, integração social, constitucionalismo, trabalho e vida, relevância social, detalhados no Quadro 1. 


\begin{tabular}{|c|c|}
\hline $\begin{array}{l}\text { Compensação Justa } \\
\text { e } \\
\text { Adequada }\end{array}$ & $\begin{array}{l}\text { Relaciona o pagamento e os fatores do trabalho, como } \\
\text { treinamento, responsabilidade e condições de trabalho. Fatores } \\
\text { como a oferta e procura de mercado, a média salarial de uma } \\
\text { população e a participação nos lucros e resultados da empresa } \\
\text { representam os indicadores que determinam o quão justo é o } \\
\text { pagamento. Dois elementos são importantes para instaurar a } \\
\text { qualidade de vida no trabalho:renda adequada e compensação } \\
\text { justa. }\end{array}$ \\
\hline $\begin{array}{l}\text { Condições de } \\
\text { Trabalho }\end{array}$ & $\begin{array}{l}\text { Discute as condições físicas e a jornada de trabalho às quais } \\
\text { o trabalhador é submetido em sua função. As variáveis } \\
\text { consideradas são: pagamento de horas extras para trabalhos } \\
\text { que ultrapassem a carga prevista; condições de trabalho que } \\
\text { minimizem o risco de acidentes e/ou doenças ligadas ao } \\
\text { trabalho; imposição de limites de idade, quando o trabalho } \\
\text { pode ser prejudicial para determinada faixa etária. }\end{array}$ \\
\hline $\begin{array}{l}\text { Uso e } \\
\text { Desenvolvimento } \\
\text { de Capacidades }\end{array}$ & $\begin{array}{l}\text { Os diferentes postos de trabalho possuem níveis diferenciados } \\
\text { de exigência no que tange o desenvolvimento de habilidades } \\
\text { e conhecimentos e cinco variáveis são necessárias para que } \\
\text { haja o pleno desenvolvimento destes:autonomia; múltiplas } \\
\text { habilidades;perspectiva e informação;trabalho como um } \\
\text { todo;planejamento. }\end{array}$ \\
\hline $\begin{array}{l}\text { Oportunidade } \\
\text { de Crescimento e } \\
\text { Segurança }\end{array}$ & $\begin{array}{l}\text { Trata das oportunidades de crescimento profissional do } \\
\text { funcionário, seja por meio de enriquecimento curricular ou } \\
\text { de uma promoção de cargo. Também, analisa segurança e } \\
\text { estabilidade no trabalho. Os fatores de influência neste critério } \\
\text { são:desenvolvimento;aplicações futuras; oportunidades de } \\
\text { avanço. }\end{array}$ \\
\hline $\begin{array}{c}\text { Integração Social } \\
\text { na Organização }\end{array}$ & $\begin{array}{l}\text { Engloba os aspectos ligados ao relacionamento pessoal e } \\
\text { autoestima no local de trabalho. Os fatores de influência deste } \\
\text { critério são:preconceito; igualdade social; mobilidade social; } \\
\text { companheirismo; senso comunitário; troca de informações. }\end{array}$ \\
\hline Constitucionalismo & $\begin{array}{l}\text { Os membros de uma empresa são afetados pelas decisões } \\
\text { tomadas, que podem favorecer interesses pessoais na empresa. } \\
\text { Nesse contexto, deve haver o constitucionalismo para proteger } \\
\text { os trabalhadores de ações arbitrárias. Os pontos de influência } \\
\text { no constitucionalismo são:privacidade; liberdade de expressão; } \\
\text { equidade; igualdade perante a lei. }\end{array}$ \\
\hline Trabalho e Vida & $\begin{array}{l}\text { As experiências vivenciadas no trabalho refletem positiva ou } \\
\text { negativamente na vida pessoal e nas relações. A jornada de } \\
\text { trabalho exaustiva pode causar sérios problemas familiares. } \\
\text { Se o trabalho não consome tanto tempo e não proporciona } \\
\text { tamanho desgaste físico, o trabalhador, em seu tempo livre, } \\
\text { pode realizar mais atividades de lazer na presença de sua } \\
\text { família. }\end{array}$ \\
\hline
\end{tabular}




\begin{tabular}{|l|l|}
\hline Relevância Social & $\begin{array}{l}\text { A responsabilidade social praticada pela empresa afeta o } \\
\text { trabalhador, de forma a melhorar a sua autoestima. Dentre } \\
\text { as atividades de responsabilidade social, podem ser citadas: } \\
\text { redução da emissão de poluentes, reaproveitamento do lixo, } \\
\text { alianças com países desenvolvidos, participação em programas } \\
\text { de auxílio às populações de baixa renda. }\end{array}$ \\
\hline
\end{tabular}

Fonte: Adaptado de Timossi et al. (2009).

\section{MÉTODO DE PESQUISA}

A pesquisa caracteriza-se como exploratória e descritiva,em relação os objetivos, e bibliográfica, quanto aos procedimentos técnicos (GIL, 2002). Na busca de maior compreensão do problema que permeia este estudo, utilizou-se uma abordagem quanti-qualitativa (ARAUJO; GOMES; LOPES, 2011; GOMES; ARAÚJO, 2005; MAY, 2004).

São inúmeros tipos de estudos que compõem a pesquisa descritiva, sendo que a maior característica delas está na utilização de técnicas padronizadas de coleta de dados como, por exemplo, o questionário.Gil (2002)ainda associa as pesquisas descritiva e exploratória ressaltando que a utilização simultânea delas é realizada em casos de estudo de atuações práticas.

O método utilizado associa duas perspectivas, sendo elas a pesquisa bibliográfica, por sua estrutura,e o estudo de caso que, conforme Fonseca (2002), é uma investigação realizada sobre uma situação específica, que pode ser única em determinados aspectos, com o objetivo de descobrir o que há nela de mais essencial e característico. Um dos benefícios da adoção do estudo de caso é a possibilidade de o pesquisador se concentrar em um aspecto e constatar suas causas, em razão de o pesquisador não possuir controle sobre os eventos (MORESI, 2003).

A unidade de análise é um estabelecimento onde está instalada umapet shop e clínica veterinária, que será tratada por 'X Pet Shop e Veterinária', para fins de sigilo que resguardam os dados desta empresa. Trata-se de uma empresa de pequeno porte, que além dos serviços recorrentes de cuidados estéticos e de entretenimento para os animais, oferece serviços de veterinária. Localizada na zona sul de Porto Alegre (RS), a loja está no mercado há vinte e três anos, atualmente conta com dezesseis funcionários em seu quadro de pessoal, composto por: dois vendedores, quatro esteticistas, um tosador, um motorista, um auxiliar de limpeza, três veterinários, o gerente geral e os três sócios. Levando em consideração o porte da empresa e o número de funcionários, a amostra desta pesquisa será a totalidade de colaboradores da empresa.

Antes da aplicação final foi realizado um pré-teste do questionário, que tem por finalidade a identificação de possíveis dificuldades no preenchimento do instrumento de avaliação por parte da população desta 
pesquisa (FOUWLER JR, 2011; NOBRE, 2012). O pré-teste refere-se ao teste do questionário em uma amostra menor de entrevistados, que possuam o mesmo perfil dos respondentes finais, com o intuito de identificar e eliminar problemas potenciais (MALHOTRA, 2012). Dessa forma, o pré-teste foi aplicado no dia 30 de março de 2016, participaram deste piloto quatro respondentes, escolhidos aleatoriamente, todos colaboradores de pet shops.Os pré-testes foram entregues em envelopes pardos, com uma prévia explicação sobre o que é QVT, a fim de elucidar o tema do questionário.

Após o pré-teste, houve uma reformulação no layout do questionário, para tornar sua apresentação mais enxuta. Também foi constatada a necessidade de inclusão de dados de identificação, como faixa etária, sexo e escolaridade, com a intenção de detectar variações no nível de satisfação de QVT a partir destas variáveis.

Os dados do estudo de caso foram coletados através de um questionário estruturado com 38 perguntas, distribuídas entre perguntas fechadas para análise quantitativa e três perguntas abertas para análise qualitativa. As questões foram dispostas no questionário de acordo com distribuição das dimensões de Walton (1973). Utilizou-se a escala de Likert, cujo modelo propõe que os respondentes atribuam uma medida de concordância com a afirmação descrita (JUNIOR; COSTA, 2014).

A aplicação do questionário foi realizada na sede da empresa, no dia 24 de abril de 2016 no período da manhã. Foramdadasas instruções de preenchimento, e tambémfoi feita a explicação sobre o significado da QVT, com o intuito de sanar eventuais dúvidas. Os questionários foram entregues em envelopes pardossem identificação do respondente, e devolvidos dentro destes mesmos envelopes, a fim de manter o padrão da pesquisa anônima.

\subsection{Forma de análise de dados}

O tratamento estatístico foi feito em planilhas no Microsoft Office Excel, que auxiliou na análise das informações, permitindo que posteriormente os dados fossem tabulados em gráficos e tabelas, para assim serem interpretados. Para melhor analisar os obtidos foi calculado o Ranking Médio (RM), de acordo com a frequência de respostas obtidas que, conforme Oliveira (2005) ocorre por meio da atribuição de pontuação determinadaaos indicadores, associando esta à frequência das respostas obtidas.

Assim sendo, com o intuito de viabilizar o cálculo do RM, foram atribuídos graus de 1 a 5 , conforme a importância de cada indicador da escala de Likert. Na escala os índices de avaliação negativa, nesse caso os equivalentes a muito insatisfeito e insatisfeito, receberam graus 1 e 2, respectivamente. Os índices positivos da escala, logo o muito satisfeito e o insatisfeito, receberam graus 4 e 5, enquanto o valor 3 foi atribuído ao índice neutro. 
Em relação às perguntas abertas, estas serão analisadas de forma qualitativa, através da análise de conteúdo que, conforme Gil (2002), possibilita a descrição do conteúdo latente ocorrido nas comunicações. A análise de conteúdo será feita com base nas dimensões de Walton, que permeiam esta pesquisa, possibilitando sejam sugeridas ações para melhorar o índice de satisfação com a QVT.

\section{ANÁLISE E DISCUSSÃO DOS RESULTADOS}

Nesta seção serão apresentados os resultados obtidos a partir da aplicação dos questionários nos funcionários da X Pet Shop eVeterinária. Os dados obtidos foram analisados visando atingir os objetivos da presente pesquisa, ou seja, analisar a qualidade de vida no trabalho na $\mathrm{X}$ Pet Shop eVeterinária.

A partir da primeira parte do questionário, em que foram solicitados dados para formação do perfil do entrevistado, foi possível a analisá-lo quanto aos aspectos de faixa etária, nível de instrução e sexo.O maior número de entrevistados está inserido na faixa etária entre 18 e 28 anos de idade, o que representa $50 \%$ do total da população da pesquisa. O intervalo de idade de 29 a 39 anos, e de 40 a 50 anos, respondem por $25 \%$ cada um. Pode-se concluir desta forma que a maior parte dos entrevistados encontra-se numa categoria de população jovem no que tange a idade, conforme categoriza o IBGE (1999).

A segunda variável demográfica do questionário foi elaborada tendo como objetivo conhecer o nível de instrução dos respondentes. Os resultados obtidos a partir desta variável refletem que $63 \%$ dos funcionários possuem ensino superior, o que engloba em andamento e completo, e $37 \%$ possuem formação até o ensino médio.A última pergunta demográfica do questionário foi elaborada para estratificar a população por sexo.Identificou-se que $56 \%$ dos colaboradores pertencem ao sexo feminino e $44 \%$ ao sexo masculino.

\subsection{Análise das dimensões de Walton para a amostra}

O questionário foi estruturado em duas partes, sendo a primeira com variáveis demográficas, com o intuito de traçar o perfil do respondente, e a segunda parte dividida em oito blocos, que correspondem às oito dimensões de Walton, cada qual contendo determinadas variáveis para medição.

O Quadro 2expõe resumidamente os resultados da pesquisa elaborada. Na primeira coluna estão dispostas as dimensões do modelo de QVT de Walton. Diretamente ligadas às dimensões estão suas variáveis correspondente, previamente determinadas para análise do nível de satisfação dos colaboradores.Por fim, encontra-se a escala do tipo Likert utilizada para medição, cuja orientação ao entrevistado foi que escolhesse apenas um dos indicadores para cada questão, de acordo com sua satisfação no trabalho. A escala foi representada por 5 pontos, cujo grau de satisfação variava entre os 
indicadores MI (Muito Insatisfeito), I (Insatisfeito), N (Neutro), S (Satisfeito) e MS (Muito Satisfeito).

Quadro 2 - Escala de avaliação da QVT

\begin{tabular}{|c|c|c|c|c|c|c|}
\hline \multirow[t]{2}{*}{ DIMENSÕES } & \multirow[t]{2}{*}{ VARIÁVEIS } & \multicolumn{5}{|c|}{$\begin{array}{l}\text { ESCALA DE } \\
\text { AVALIAÇÃO }\end{array}$} \\
\hline & & MI & I & $\mathbf{N}$ & $\mathrm{S}$ & MS \\
\hline \multirow{4}{*}{$\begin{array}{c}\text { COMPENSAÇÃO JUSTA E } \\
\text { ADEQUADA }\end{array}$} & $\begin{array}{l}\text { Remuneração } \\
\text { adequada }\end{array}$ & 0 & 4 & 4 & 7 & 1 \\
\hline & Equidade interna & 0 & 5 & 1 & 10 & 0 \\
\hline & Política de benefícios & 2 & 5 & 3 & 5 & 1 \\
\hline & $\begin{array}{l}\text { Política de benefícios } \\
\text { extras }\end{array}$ & 0 & 3 & 3 & 9 & 1 \\
\hline \multirow{6}{*}{ CONDIÇÕES DE TRABALHO } & Jornada de trabalho & 0 & 0 & 5 & 7 & 4 \\
\hline & Carga de trabalho & 0 & 3 & 1 & 9 & 3 \\
\hline & Uso de tecnologia & 0 & 1 & 2 & 9 & 4 \\
\hline & Ambiente físico & 0 & 0 & 2 & 5 & 9 \\
\hline & Segurança & 0 & 1 & 2 & 8 & 5 \\
\hline & Nível de desgaste & 0 & 3 & 5 & 8 & 0 \\
\hline \multirow{5}{*}{$\begin{array}{c}\text { USO OU DESENVOLVIMENTO } \\
\text { DE CAPACIDADES }\end{array}$} & Autonomia & 1 & 0 & 6 & 8 & 1 \\
\hline & $\begin{array}{l}\text { Relevância das } \\
\text { atividades exercidas }\end{array}$ & 1 & 1 & 5 & 7 & 2 \\
\hline & Feedback & 0 & 3 & 5 & 7 & 1 \\
\hline & $\begin{array}{l}\text { Uso de capacidades/ } \\
\text { habilidades }\end{array}$ & 0 & 0 & 7 & 8 & 1 \\
\hline & Responsabilidade & 0 & 1 & 5 & 7 & 3 \\
\hline \multirow{4}{*}{$\begin{array}{c}\text { OPORTUNIDADE DE } \\
\text { CRESCIMENTO E SEGURANÇA }\end{array}$} & $\begin{array}{l}\text { Crescimento } \\
\text { profissional }\end{array}$ & 0 & 4 & 6 & 5 & 1 \\
\hline & Capacitação & 0 & 4 & 5 & 6 & 1 \\
\hline & Desligamentos & 0 & 1 & 14 & 1 & 0 \\
\hline & $\begin{array}{l}\text { Incentivo a } \\
\text { qualificação }\end{array}$ & 2 & 5 & 8 & 0 & 1 \\
\hline \multirow{4}{*}{$\begin{array}{l}\text { INTEGRAÇÃO SOCIAL NA } \\
\text { ORGANIZAÇÃO }\end{array}$} & Respeito às diferenças & 1 & 0 & 1 & 8 & 6 \\
\hline & $\begin{array}{l}\text { Relacionamento } \\
\text { interpessoal }\end{array}$ & 0 & 0 & 3 & 5 & 8 \\
\hline & Comprometimento & 1 & 4 & 3 & 3 & 5 \\
\hline & Valorização & 0 & 1 & 6 & 8 & 1 \\
\hline
\end{tabular}




\begin{tabular}{|c|c|c|c|c|c|c|}
\hline \multirow[t]{2}{*}{ DIMENSÕES } & \multirow[t]{2}{*}{ VARIÁVEIS } & \multicolumn{5}{|c|}{$\begin{array}{l}\text { ESCALA DE } \\
\text { AVALIAÇÃO }\end{array}$} \\
\hline & & MI & $\mathrm{I}$ & $\mathbf{N}$ & $\mathbf{S}$ & MS \\
\hline \multirow{4}{*}{ CONSTITUCIONALISMO } & Direitos trabalhistas & 0 & 0 & 1 & 12 & 3 \\
\hline & $\begin{array}{l}\text { Liberdade de } \\
\text { expressão }\end{array}$ & 0 & 0 & 2 & 9 & 5 \\
\hline & Normas & 0 & 0 & 2 & 9 & 5 \\
\hline & $\begin{array}{l}\text { Tratamento impessoal } \\
\text { e igualitário }\end{array}$ & 0 & 1 & 4 & 7 & 4 \\
\hline \multirow{3}{*}{ TRABALHO E VIDA } & $\begin{array}{l}\text { Impacto do trabalho } \\
\text { na vida pessoal }\end{array}$ & 0 & 4 & 5 & 6 & 1 \\
\hline & $\begin{array}{l}\text { Impacto do trabalho } \\
\text { no lazer }\end{array}$ & 0 & 4 & 5 & 6 & 1 \\
\hline & $\begin{array}{l}\text { Carga de trabalho } x \\
\text { Folgas }\end{array}$ & 1 & 3 & 3 & 5 & 4 \\
\hline \multirow{5}{*}{ RELEVÂNCIA SOCIAL } & Realização pessoal & 0 & 1 & 6 & 4 & 5 \\
\hline & $\begin{array}{l}\text { Imagem da } \\
\text { organização }\end{array}$ & 0 & 0 & 0 & 9 & 7 \\
\hline & $\begin{array}{l}\text { Responsabilidade } \\
\text { Social }\end{array}$ & 0 & 1 & 8 & 4 & 3 \\
\hline & $\begin{array}{l}\text { Qualidade dos } \\
\text { serviços e produtos }\end{array}$ & 0 & 1 & 0 & 8 & 7 \\
\hline & $\begin{array}{l}\text { Práticas de recursos } \\
\text { humanos }\end{array}$ & 0 & 0 & 5 & 8 & 3 \\
\hline
\end{tabular}

Fonte: Elaborado pelos autores (2016).

\subsubsection{Quanto à compensação justa e adequada}

A compensação justa e adequada está relacionada à remuneração compatível com trabalho realizado, à equidade de salário entre os colegas e em relação ao mercado externo ea benefícios que incrementem a renda do trabalhador (TIMOSSI et al., 2009).A remuneração adequada é necessária para a satisfação das necessidades pessoais e dos padrões culturais, sociais e econômicos da sociedade na qual o trabalhador está inserido (SANTOS, 2012).

Avaliando o cenárioem relação à remuneração adequada percebe-se que $44 \%$ do total dos funcionários se manifestaram satisfeitos com o salário recebido, $6 \%$ se declaram muito satisfeitos. Identificou-se o percentual de $25 \%$ de funcionários manifestaram insatisfação e $25 \%$ se revelaram neutros. A equidade salarial pode ser definida como a propensão das pessoas em comparar seus ganhos em relação aos colegas de trabalho e a outros profissionais da mesma área (MACHAVA, 2012). 
Em relação aos resultados obtidos na variável política de benefícios, constata-se um equilíbrio entre as respostas, sendo que $31 \%$ dos respondentes se assumiram satisfeitos, mesma porcentagem dos colaboradores que se declararam insatisfeitos. $\mathrm{O}$ restante do quadro de funcionários se dividiu em $19 \%$ que se revelaram neutros, $13 \%$ que avaliaram como muito insatisfatória a oferta de benefícios e $6 \%$ dos empregados se manifestaram muito satisfeitos.

O plano de benefícios é um meio de atender as necessidades do funcionário, cujo impacto é capaz de proporcionar a vida tranquila e produtiva, tanto no caráter profissional quanto no pessoal (SANTOS, 2012). Em conjunto a esta variável se buscou saber o nível de satisfação em relação aos benefícios extras, referentes aos benefícios que não são obrigações do empregador, como vale-alimentação e auxílio creche. Como resultado, identificou-se que 56\% dos colaboradores manifestaram satisfação, $19 \%$ insatisfação, mesmo percentual identificado no grupo que se declarou neutro, e $6 \%$ do grupo se manteve muito satisfeito.

Na Tabela 1, pode-se observar o panorama geral do nível de satisfação da dimensão compensação justa e adequada na QVT dos colaboradores da X Pet Shop eVeterinária. Observa-se que as variáveis: política de benefícios extras, equidade interna e remuneração adequada com índices superiores a 3 são as favoráveis a avaliação de satisfação na Qualidade de Vida no Trabalho do quadro de funcionários da X Pet Shop eVeterinária. Enquanto a variável política de benefícios apresenta grau de 2,88 de avaliação, sendo considerada uma variável que compromete o alcance da QVT.

Tabela 1 - Avaliação da Compensação Justa e Adequada

\begin{tabular}{|c|c|c|c|c|c|c|c|}
\hline \multirow[t]{2}{*}{ DIMENSÃO } & \multirow[t]{2}{*}{ VARIÁVEIS } & \multicolumn{6}{|c|}{$\begin{array}{c}\text { FREQUÊNCIA DE } \\
\text { APARIÇÃO }\end{array}$} \\
\hline & & MI & $\mathrm{I}$ & $\mathrm{N}$ & $S$ & MS & RM \\
\hline \multirow{4}{*}{$\begin{array}{c}\text { COMPENSAÇÃO } \\
\text { JUSTA E ADEQUADA }\end{array}$} & $\begin{array}{l}\text { Política de benefícios } \\
\text { extras }\end{array}$ & - & 3 & 3 & 9 & 1 & 3,50 \\
\hline & Equidade interna & - & 5 & 1 & 10 & - & 3,31 \\
\hline & Remuneração adequada & - & 4 & 4 & 7 & 1 & 3,31 \\
\hline & Política de benefícios & 2 & 5 & 3 & 5 & 1 & 2,88 \\
\hline
\end{tabular}

Fonte: Elaborada pelos autores (2016).

\subsubsection{Quanto às condições de trabalho}

O critério condições de trabalho investiga a jornada de trabalho à qual o trabalhador é submetido em seu emprego, à carga de trabalho exercida e o impacto por elas causado, além de apurar também as condições do ambiente 
físico.Para isso, são analisados materiais e equipamentos disponibilizados, a iluminação, higiene, organização e barulho (SANTOS, 2012).

Observa-se que $44 \%$ do quadro de funcionários estásatisfeito com a jornada de trabalho, $31 \%$ se declaram neutros e $25 \%$ muito satisfeitos.Em relação à carga de trabalho, verifica-se que $56 \%$ dos empregados manifestaram satisfação, $19 \%$ dos que se assumiram muito satisfeitos, $19 \%$ se declararam insatisfeitos e os outros $6 \%$ neutros.A respeito do uso de tecnologia no trabalho, constata-se que $56 \%$ dos trabalhadores estão satisfeitos, $25 \%$ muito satisfeitos, $13 \%$ estão insatisfeitos e o $6 \%$ restante insatisfeitos.

$\mathrm{O}$ ambiente físico investiga se o local de trabalho possui condições que forneçam bem-estar, organização e segurança (HITZ, 2010), pois a promoção da saúde no local de trabalho deve ser um objetivo estratégico para os empregadores (GUEVEL et al., 2015).No que se refere ao ambiente físico, 56\% dos colaboradores se manifestaram muito satisfeitos, $31 \%$ satisfeitos e $13 \%$ que se declaram neutros.

A variável segurança no trabalho apresentou $50 \%$ de funcionários satisfeitos, $31 \%$ como muito satisfeitos, $13 \%$ de neutros e $6 \%$ que se manifestaram insatisfeitos. As respostas para a questão de nível de desgaste causado pelas condições de trabalho mostram que $50 \%$ dos funcionários estão satisfeitos com o impacto físico e psicológico, ao passo que $31 \%$ do grupo se mantiveram neutros e $19 \%$ se declaram insatisfeitos.

Com o intuito de ter uma visão do nível de satisfação da categoria condições de trabalho foi calculado RM nos dados obtidos. $\mathrm{O}$ resultado pode ser visto na Tabela 2.

Tabela 2 - Avaliação das Condições de trabalho

\begin{tabular}{|c|c|c|c|c|c|c|c|}
\hline \multirow[t]{2}{*}{ DIMENSÃO } & \multirow[t]{2}{*}{ VARIÁVEIS } & \multicolumn{6}{|c|}{$\begin{array}{c}\text { FREQUÊNCIA DE } \\
\text { APARIÇÃO }\end{array}$} \\
\hline & & MI & $\mathrm{I}$ & $\mathrm{N}$ & $S$ & MS & $\mathbf{R M}$ \\
\hline \multirow{6}{*}{$\begin{array}{l}\text { CONDIÇÕES DE } \\
\text { TRABALHO }\end{array}$} & Ambiente físico & - & - & 2 & 5 & 9 & 4,44 \\
\hline & Segurança & - & 3 & 2 & 8 & 5 & 4,06 \\
\hline & Uso de tecnologia & - & 1 & 2 & 9 & 4 & 4,00 \\
\hline & Jornada de trabalho & - & - & 5 & 7 & 4 & 3,94 \\
\hline & Carga de trabalho & - & 3 & 1 & 9 & 3 & 3,75 \\
\hline & Nível de desgaste & - & 3 & 5 & 8 & - & 3,31 \\
\hline
\end{tabular}

Fonte: Elaborado pelos autores (2016).

Analisando as informações da Tabela 2, verifica-se que as todas as variáveis do critério condições de trabalho apresentam resultado superior a 3 , 
caracterizando-se como fatores satisfatórios e favoráveis ao alcance da QVT na unidade de análise.

\subsubsection{Quanto ao uso e desenvolvimento de capacidades}

A autonomia torna o empregado capaz de tomar suas próprias decisões em relação à atividade que desempenha (SANTOS, 2012). Analisando os resultados da variável autonomia observa-se que $50 \%$ dos respondentes estão satisfeitos, $38 \%$ são neutros, $6 \%$ do grupo se declarou insatisfeito, mesmo percentual de quem se declarou muito satisfeito. Em complemento à autonomia, foi analisada a variável responsabilidade, e os resultados mostraram que 38\% dos entrevistados estão satisfeitos, 31\% se manifestaram neutros, $19 \%$ alegaram estar muito satisfeitos e os últimos 13\% declaram estar insatisfeitos.No que se refere a variável relevância das atividades exercidas, o estudo evidencia que $44 \%$ dos respondentes estão satisfeitos, $31 \%$ se declararam neutros e $13 \%$ muito satisfeitos.

Em relação ao indicadorfeedback, verifica-se que $44 \%$ dos funcionários estão satisfeitos, $31 \%$ neutros, $19 \%$ insatisfeitos e $6 \%$ muito satisfeitos. Segundo Santos (2012) ressalta, o feedback é uma informação valiosa, pois a partir dele o funcionário recebe informações sobre a avaliação de seu desempenho, permitindo que ocorram melhoras contínuas.A partir do indicador uso de capacidade e habilidades, observa-se que $50 \%$ dos funcionários estão satisfeitos, $44 \%$ se manifestaram neutros e $6 \%$ muito satisfeito

Para obter uma visão panorâmica dos resultados obtidos na medição de QVT na categoria uso e desenvolvimento de capacidades, o cálculo do ranking médio foi utilizado, conforme dados da Tabela 3.

Tabela 3 - Avaliação do Uso e desenvolvimento de capacidades

\begin{tabular}{|c|c|c|c|c|c|c|c|}
\hline \multirow{2}{*}{ DIMENSÃO } & \multirow[t]{2}{*}{ VARIÁVEIS } & \multicolumn{6}{|c|}{$\begin{array}{c}\text { FREQUÊNCIA DE } \\
\text { APARIÇÃO }\end{array}$} \\
\hline & & MI & I & $\mathrm{N}$ & $S$ & MS & $\mathbf{R M}$ \\
\hline \multirow{5}{*}{$\begin{array}{c}\text { USO OU } \\
\text { DESENVOLVIMENTO } \\
\text { DE CAPACIDADES }\end{array}$} & Responsabilidade & - & 1 & 5 & 7 & 2 & 3,75 \\
\hline & $\begin{array}{l}\text { Uso de capacidades / } \\
\text { habilidades }\end{array}$ & - & - & 7 & 8 & 1 & 3,63 \\
\hline & Autonomia & 1 & - & 6 & 8 & 1 & 3,50 \\
\hline & $\begin{array}{l}\text { Relevância das atividades } \\
\text { exercidas }\end{array}$ & 1 & 1 & 5 & 7 & 2 & 3,50 \\
\hline & Feedback & - & 3 & 5 & 7 & 1 & 3,38 \\
\hline
\end{tabular}

Fonte: Elaborado pelos autores (2016). 
Examinando os dados ordenados da Tabela 3, observa-se que possuindo um RM de peso central todas as variáveis são categorizadas comofavoráveis a QVT.

\subsubsection{Quanto à oportunidade de crescimento e segurança}

Oportunidade de crescimento permite observar o quanto a empresa valoriza o funcionário, investigando possibilidades de desenvolvimento e a segurança no emprego (HITZ, 2010). Quanto à possibilidade crescimento profissional dentro da empresa, 38\% dos entrevistados se manifestaram neutros, $31 \%$ se declararam satisfeitos, $25 \%$ insatisfeitos e $6 \%$ muito satisfeitos.

A partir da análise do indicador de capacitação profissional, observase que $38 \%$ do grupo estão satisfeitos, $31 \%$ não estão nem satisfeitos, nem insatisfeitos, $25 \%$ dos entrevistados estão insatisfeitos e o índice de muito satisfeitos se manteve em $6 \%$. A investigação da capacitação profissional está relacionada a desenvolvimento e capacitação que ofereça a possibilidade de aprimorar os conhecimentos (MACHAVA, 2012). O conhecimento obtido através da aprendizagem auxilia nas competências profissionais, contribuindo com as necessidades do empregado e da empresa (SIRGY et al., 2001). Em conjunto a esta questão, se buscou investigar o incentivo da empresa à qualificação profissional de seus colaboradores. Os resultados obtidos indicaram que $50 \%$ dos colaboradores se declararam neutros, $31 \%$ insatisfeitos, $13 \%$ muito insatisfeitos e $6 \%$ muito satisfeitos.

Também foi investigado o nível de satisfação dos colaboradores com as situações de demissão de funcionários, $88 \%$ se declararam neutros, $6 \%$ satisfeitos e $6 \%$ insatisfeitos. A questão das demissões relacionam-se à segurança no emprego, possibilitando investigar o sentimento de segurança em relação a preservação do emprego (TIMOSSI et al., 2009)

Para uma visualização geral do nível de satisfação da dimensão oportunidade de crescimento e segurança, podem-se observar na Tabela 4 os resultados da aplicação do cálculo do RM.

Tabela 4- Avaliação da Oportunidade de crescimento e segurança

\begin{tabular}{c|l|c|c|c|c|c|c}
\hline \multirow{2}{*}{ DIMENSÃO } & \multicolumn{5}{|c|}{ FREQUÊNCIA DE } \\
\cline { 3 - 8 } & & \multicolumn{5}{c}{ APARIÇÁO } \\
\cline { 2 - 8 } & Capacitação & MI & I & N & S & MS & RM \\
\hline \multirow{3}{*}{$\begin{array}{c}\text { OPORTUNIDADE } \\
\text { DE CRESCIMENTO E } \\
\text { SEGURANÇA }\end{array}$} & Crescimento profissional & - & 4 & 6 & 5 & 1 & 3,19 \\
\cline { 2 - 8 } & Desligamentos & - & 1 & 14 & 1 & - & 3,00 \\
\cline { 2 - 8 } & Incentivo a capacitação & 2 & 5 & 8 & - & 1 & 2,56 \\
\hline
\end{tabular}

Fonte: Elaborada pelos autores (2016). 
A partir dos resultados da tabela 4 indicam que as variáveis crescimento profissional, capacitação e desligamentos são favoráveis ao alcance da QVT, sendo que a variável incentivo a capacitação apresenta grau abaixo de 3, categorizando-se como uma categoria que impacta na QVT dos colaboradores.

\subsubsection{Quanto à integração social na organização}

A QVT está relacionada à convivência saudável entre as pessoas na empresa e, conforme Santos (2012), é possível medir este critério através da existência de do respeito às individualidades. A partir do questionário aplicado, observa-se que com relação aos níveis de satisfação com a questão de respeito às diferenças 50\% dos empregados se demonstram satisfeitos, $38 \%$ muito satisfeitos, $6 \%$ neutros e $6 \%$ muito insatisfeitos.Em conjunto à igualdade de oportunidade, foi investigada a satisfação dos funcionários com relação à valorização das ideias e propostas sugeridas, os resultados da pesquisa apontaram que $50 \%$ dos funcionários se manifestaram satisfeitos, $38 \%$ neutros, $6 \%$ insatisfeitos e $6 \%$ muito satisfeitos.

Quanto à questão de relacionamento interpessoal, $50 \%$ dos entrevistados se manifestaram muito satisfeitos, $31 \%$ satisfeitos e $19 \%$ neutros. Fatores como as relações sociais contribuem com a qualidade de vida e satisfação no trabalho (REQUENA, 2003), a existência de um relacionamento interpessoal entre os empregados promove o respeito entre os mesmos (HITZ, 2010). Concomitante a esta última variável buscou-se analisar a percepção dos colaboradores em relação ao comprometimento dos colegas, 31\% dos funcionários declararam muito satisfeitos, $25 \%$ insatisfeitos, $19 \%$ permaneceram neutros,sendo este último,o mesmo percentual registrado de funcionários satisfeitos e, por fim, $6 \%$ do total da amostra se manifestaram muito insatisfeitos.

Na Tabela 5 é possível verificar o impacto geral do critério integração social na Qualidade de Vida no Trabalho dos funcionários da empresa.

Tabela 5- Avaliação da Integração social na organização

\begin{tabular}{|c|c|c|c|c|c|c|c|}
\hline \multirow[t]{2}{*}{ DIMENSÃO } & \multirow[t]{2}{*}{ VARIÁVEIS } & \multicolumn{6}{|c|}{$\begin{array}{l}\text { FREQUÊNCIA DE } \\
\text { APARIÇÃO }\end{array}$} \\
\hline & & MI & $\mathrm{I}$ & $\mathrm{N}$ & $S$ & MS & $\mathbf{R M}$ \\
\hline \multirow{4}{*}{$\begin{array}{l}\text { INTEGRAÇÃO SOCIAL } \\
\text { NA ORGANIZAÇÃO }\end{array}$} & $\begin{array}{l}\text { Relacionamento } \\
\text { interpessoal }\end{array}$ & - & - & 3 & 5 & 8 & 4,31 \\
\hline & Respeito às diferenças & 1 & - & 1 & 8 & 6 & 4,13 \\
\hline & Valorização & - & 1 & 6 & 8 & 1 & 3,56 \\
\hline & Comprometimento & 1 & 4 & 3 & 3 & 5 & 3,44 \\
\hline
\end{tabular}

Fonte: Elaborado pelos autores (2016). 
Analisando a Tabela 5 se verifica que o todas as variáveis atingiram grau maior que 3, caracterizando a dimensão como um fator favorável ao alcance da Qualidade de Vida no Trabalho.

\subsubsection{Quanto ao constitucionalismo}

O cumprimento dos direitos trabalhistas atesta se a organização cumpre os direitos dos trabalhadores previstos em lei (MACHAVA, 2012). Quanto a esse aspecto, 75\% dos colaboradores se consideram satisfeitos, 19\% muito satisfeitos e $6 \%$ do grupo se manifestou neutro. Analisando a categoria liberdade de expressão, 75\% sinalizaram-se satisfeitos, 13\% muito satisfeitos e $13 \%$ de funcionários se manifestaram neutros.

Em relação a normas e regras estabelecidas pela empresa, observa-se $75 \%$ se mantiveram satisfeitos, $13 \%$ dos funcionários permaneceram muito satisfeitos, mesmo percentual observado de respondentes neutros. Hitz (2010) especifica que este indicador está associado à divulgação clara das normas e regras da empresa. Quanto à categoria tratamento impessoal e igualitário, observa-se ainda a predominância da avaliação positiva, sendo esta composta por $44 \%$ de satisfeitos e $15 \%$ de muito satisfeitos, contudo nota-se o aumento de neutros e o aparecimento de insatisfeitos, sendo estes representados por $25 \%$ e $6 \%$ do total, respectivamente.

Na Tabela 6 pode-se observar o panorama geral da satisfação referente ao critério tratamento pessoal e igualitário no trabalho.

Tabela 6 - Avaliação do Constitucionalismo

\begin{tabular}{l|l|c|c|c|c|c|c}
\hline \multirow{2}{*}{ DIMENSÃO } & \multirow{2}{*}{ VARIÁVEIS } & \multicolumn{5}{c}{ FREQUÊNCIA DE } \\
\cline { 3 - 9 } & & MI & I & N & S & MS & RM \\
\hline \multirow{4}{*}{ CONSTITUCIONALISMO } & Liberdade de expressão & - & - & 2 & 9 & 5 & 4,19 \\
\cline { 2 - 9 } & Normas & - & - & 2 & 9 & 5 & 4,19 \\
\cline { 2 - 8 } & Direitos trabalhistas & - & - & 1 & 12 & 3 & 4,13 \\
\cline { 2 - 8 } & $\begin{array}{l}\text { Tratamento impessoal e } \\
\text { igualitário }\end{array}$ & - & 1 & 4 & 7 & 4 & 3,88 \\
\hline
\end{tabular}

Fonte: Elaborado pelos autores (2016).

A partir da análise dos indicadores na Tabela 6, percebe-se que os resultados referentes ao constitucionalismo no geral foram satisfatórios na avaliação da percepção dos funcionários, sendo que os todos os indicadores superior a 3, o que representa que estas são variáveis favoráveis ao alcance da QVT. 


\subsubsection{Quanto ao trabalho e vida}

As experiências dos trabalhadores podem afetar de forma positiva ou negativa na vida pessoal e social (HITZ, 2010), e a finalidade deste critério é avaliar a relação do trabalho e do tempo com a família, lazer, balanceamento da jornada de trabalho e assim mensurar o impacto na QVT (SANTOS, 2012). Analisando os resultados obtidos no indicador impacto do trabalho na vida pessoal, verifica-se que 38\% dos funcionários se manifestaram satisfeitos, 31\% se declararam neutros e um percentual de $25 \%$ insatisfeitos, havendo ainda $6 \%$ que se declararam muito satisfeitos.

No que se refere ao impacto do trabalho no lazer dos funcionários, 38\% se declararam satisfeitos, $31 \%$ de neutros, $25 \%$ de insatisfeitos e $6 \%$ a muito satisfeitos. Em relação à carga de trabalho versus as folgas recebidas, observase que $38 \%$ dos funcionários se declararam neutros quanto à política de folgas, $31 \%$ se manifestaram satisfeitos, $25 \%$ muito satisfeitos e $6 \%$ insatisfeitos.

Na Tabela 7 se pode verificar através da aplicação do Ranking Médio, o resultado geral da dimensão trabalho e vida na avaliação dos funcionários da $\mathrm{X}$ Pet Shop eVeterinária considerando todas variáveis pesquisadas.

Tabela 7- Avaliação do Trabalho e Vida

\begin{tabular}{c|l|c|c|c|c|c|c}
\hline \multirow{2}{*}{ DIMENSÃO } & \multicolumn{1}{|c|}{ VARIÁVEIS } & \multicolumn{5}{c}{ FREQUÊNCIA DE } \\
\cline { 3 - 9 } & \multicolumn{1}{|c}{ MI } & I & N & S & MS & RM \\
\hline \multirow{4}{*}{ TRABALHO E VIDA } & Carga de trabalho x Folgas & 1 & 2 & 3 & 7 & 3 & 3,56 \\
\cline { 2 - 9 } & $\begin{array}{l}\text { Impacto do trabalho no } \\
\text { lazer }\end{array}$ & - & 2 & 6 & 6 & 2 & 3,50 \\
\cline { 2 - 9 } & $\begin{array}{l}\text { Impacto do trabalho na } \\
\text { vida pessoal }\end{array}$ & 1 & 2 & 6 & 6 & 2 & 3,50 \\
\hline
\end{tabular}

Fonte: Elaborado pelos autores (2016).

Na tabela 7, observa-se que as variáveis do critério se estabelecem como pontos favoráveis no alcance da QVT, dadas as médias das variáveis teremsidosuperior a 3 .

\subsubsection{Quanto à relevância social}

$\mathrm{O}$ indicador imagem da empresa está associado à credibilidade da organização na percepção do funcionário (HITZ, 2010). No que se refere à imagem que o trabalhador tem da organização, 56\% se declararam satisfeitos e $44 \%$ muito satisfeitos. Quanto à realização pessoal em desempenhar o trabalho, $38 \%$ dos funcionários se manifestaram neutros, $31 \%$ de declararam muito satisfeitos, $25 \%$ satisfeitos e $6 \%$ insatisfeitos. 
Em relação à percepção da responsabilidade social da empresa, 50\% dos empregados se manifestaram neutros, $25 \%$ satisfeitos, $19 \%$ muito satisfeitos e $6 \%$ de insatisfeitos..Quanto à relevância social pelos produtos e serviços, 50\% de respondentes que se declararam satisfeitos, $44 \%$ de muito satisfeitos e os $6 \%$ restantes da amostra se mantiveram insatisfeitos.

A variável política de recursos humanos teve $50 \%$ de satisfeitos, $19 \%$ de muito satisfeitos e $31 \%$ de neutros. O indicador política de recursos humanos corresponde à responsabilidade social dos empregados que Machava (2012) descreve, ela está relacionada às práticas de emprego, em que o trabalhador pressupõe que seus familiares serão amparados em caso de ele sofrer algum infortúnio.

Na Tabela 8 se pode observar através da aplicação do RM, o panorama geral do critério relevância social na avaliação dos funcionários da X Pet Shop eVeterinária.

Tabela 8 - Avaliação da Relevância social

\begin{tabular}{|c|c|c|c|c|c|c|c|}
\hline \multirow[t]{2}{*}{ DIMENSÃO } & \multirow{2}{*}{ VARIÁVEIS } & \multicolumn{6}{|c|}{$\begin{array}{l}\text { FREQUENNCIA DE } \\
\text { APARIÇÃO }\end{array}$} \\
\hline & & MI & I & $\mathrm{N}$ & $S$ & MS & $\mathbf{R M}$ \\
\hline \multirow{5}{*}{ RELEVÂNCIA SOCIAL } & $\begin{array}{l}\text { Qualidade dos serviços e } \\
\text { produtos }\end{array}$ & - & 1 & - & 8 & 7 & 4,31 \\
\hline & $\begin{array}{l}\text { Práticas de recursos } \\
\text { humanos }\end{array}$ & - & - & 5 & 8 & 3 & 3,88 \\
\hline & Realização pessoal & - & 1 & 6 & 4 & 5 & 3,81 \\
\hline & Responsabilidade Social & - & 1 & 8 & 4 & 3 & 3,56 \\
\hline & Imagem da organização & - & - & - & 9 & 7 & 3,44 \\
\hline
\end{tabular}

Fonte: Elaborado pelos autores (2016).

A pesquisa evidencia resultado satisfatório na categoria para a variável qualidade de serviços e produtos. As demais variáveis não destoam de maneira positiva ou negativa, permanecendo na zona central.

\subsubsection{Análise das perguntas abertas}

Nesta subseção serão apresentados os resultados obtidos por meios das perguntas abertas do questionário aplicado. A fim de sugerir ações para o alcance ou melhoria dos índices de QVT, foram incluídas três perguntas abertas no questionário, cujo teor buscava saber fatores importantes e prejudiciais para a conquista da QVT e, também, uma questão onde o respondente poderia sugerir algo que na sua percepção seria importante para melhorar a QVT. 
Efetuou-se a categorização dos dados de acordo com as dimensões de Walton, verificada no Quadro 3.

Quadro 3 - Nomenclatura das dimensões para análise das perguntas abertas

\begin{tabular}{|c|c|}
\hline DIMENSÃO DE WALTON & LEGENDA - DIMENSÕES \\
\hline Compensação justa e adequada & D1 \\
\hline Condições de Trabalho & D2 \\
\hline Uso e desenvolvimento de capacidades & D3 \\
\hline Oportunidade de crescimento e segurança & D4 \\
\hline Integração social na organização & D5 \\
\hline Constitucionalismo & D6 \\
\hline Trabalho e vida & D7 \\
\hline Relevância social & D8 \\
\hline
\end{tabular}

Fonte: Elaborado pelos autores (2016).

No Quadro 4 se pode observar resumidamente a compilação das respostas, já com a aplicação da redução de dados e categorização. 
Quadro 4 - Mapeamento da Pergunta 1

\begin{tabular}{|c|c|c|c|c|c|c|c|c|c|}
\hline \multirow{2}{*}{ PERGUNTA 1} & \multirow{2}{*}{ RESPOSTAS } & \multicolumn{8}{|c|}{ DIMENSÃO } \\
\hline & & D1 & D2 & D3 & D4 & D5 & D6 & D7 & D8 \\
\hline \multirow{14}{*}{$\begin{array}{c}\text { O que você } \\
\text { considera mais } \\
\text { importante para } \\
\text { o alcance da sua } \\
\text { Qualidade de Vida } \\
\text { no Trabalho? }\end{array}$} & Folgas & & $X$ & & & & & & \\
\hline & União dos colegas & & & & & $X$ & & & \\
\hline & $\begin{array}{l}\text { Prazer em realizar o } \\
\text { trabalho }\end{array}$ & & & & & & & & $x$ \\
\hline & $\begin{array}{l}\text { Diminuição da } \\
\text { jornada de trabalho }\end{array}$ & & $x$ & & & & & & \\
\hline & Ambiente adequado & & $X$ & & & & & & \\
\hline & Conceder vales & $X$ & & & & & & & \\
\hline & $\begin{array}{l}\text { Diálogo com os } \\
\text { chefes }\end{array}$ & & & & & $x$ & & & \\
\hline & $\begin{array}{l}\text { Melhorar a } \\
\text { remuneração }\end{array}$ & $x$ & & & & & & & \\
\hline & Clima organizacional & & & & & $X$ & & & \\
\hline & Gostar do que faz & & & & & & & & $X$ \\
\hline & $\begin{array}{l}\text { Promoções de cargo } \\
\text { por merecimento }\end{array}$ & & & & & $X$ & & & \\
\hline & $\begin{array}{l}\text { Bom relacionamento } \\
\text { entre os colegas }\end{array}$ & & & & & $x$ & & & \\
\hline & $\begin{array}{l}\text { Reconhecimento pelo } \\
\text { desempenho }\end{array}$ & & & & & $X$ & & & \\
\hline & $\begin{array}{l}\text { Respeito aos diretos } \\
\text { dos trabalhadores }\end{array}$ & & & & & & $X$ & & \\
\hline
\end{tabular}

Fonte: Elaborado pelos autores (2016).

A partir das informações obtidas e transcritas no Quadro 4, pode-se observar que ao investigar qual fator os respondentes julgavam importante para o alcance da satisfação. O critério Integração Social na Organização foi o que teve maior número de respostas agrupadas à sua categoria, tendo sido citados como pontos importantes para o alcance da QVT: o relacionamento interpessoal e a valorização do funcionário.

Também, buscou-se investigarquais fatores impactam negativamente na QVT dos empregados da empresa, apresentados no Quadro 5.Verificou-se que novamente a dimensão Integração Social na Organização foi a que teve maior agrupamento, sendo seguida pela dimensão Condições de Trabalho, Uso e Desenvolvimento de Capacidades e Constitucionalismo. Fatores como falta de compromisso dos colegas, relacionamento e desvalorização dos funcionários se fizeram presentes, bem como a importância do ambiente adequado, da carga 
de trabalho adequada, falta de autonomia para tomar decisões e tratamento desigual para elevações de cargo figuraram como pontos que afetam a QVT.

Quadro 5 - Mapeamento da Pergunta 2

\begin{tabular}{|c|c|c|c|c|c|c|c|c|c|}
\hline \multirow{2}{*}{ PERGUNTA 2} & \multirow{2}{*}{ RESPOSTAS } & \multicolumn{8}{|c|}{ DIMENSÃO } \\
\hline & & D1 & D2 & D3 & D4 & D5 & D6 & D7 & D8 \\
\hline \multirow{10}{*}{$\begin{array}{c}\text { Quais fatores } \\
\text { você considera } \\
\text { que prejudicam } \\
\text { sua Qualidade } \\
\text { de Vida no } \\
\text { Trabalho? }\end{array}$} & Ambiente inadequado & & $x$ & & & & & & \\
\hline & Desvalorização & & & & & $x$ & & & \\
\hline & Tratamento desigual & & & & & & $X$ & & \\
\hline & Trabalhar em pé & & $X$ & & & & & & \\
\hline & Falta de autonomia & & & $X$ & & & & & \\
\hline & Falta de coleguismo & & & & & $x$ & & & \\
\hline & $\begin{array}{l}\text { Carga de trabalho } \\
\text { pesada }\end{array}$ & & $X$ & & & & & & \\
\hline & $\begin{array}{l}\text { Desorganização do } \\
\text { ambiente }\end{array}$ & & $x$ & & & & & & \\
\hline & $\begin{array}{l}\text { Falta de compromisso } \\
\text { dos colegas }\end{array}$ & & & & & $x$ & & & \\
\hline & $\begin{array}{l}\text { Falta de proximidade } \\
\text { entre as pessoas }\end{array}$ & & & & & $x$ & & & \\
\hline
\end{tabular}

Fonte: Elaborado pelos autores (2016).

Por fim, a pergunta aberta de número 3 instigava o colaborador a sugerir uma proposta de ação que na sua percepção poderia melhorar a QVT. O Quadro 6 apresenta o cruzamento das informações. 
Quadro 6 - Mapeamento da Pergunta 3

\begin{tabular}{|c|c|c|c|c|c|c|c|c|c|}
\hline \multirow{2}{*}{ PERGUNTA 3} & \multirow{2}{*}{ RESPOSTAS } & \multicolumn{8}{|c|}{ DIMENSÃO } \\
\hline & & D1 & D2 & D3 & D4 & D5 & D6 & D7 & D8 \\
\hline \multirow{12}{*}{$\begin{array}{c}\text { Na sua } \\
\text { opinião, o que } \\
\text { poderia ser } \\
\text { proposto para } \\
\text { a melhoria da } \\
\text { sua Qualidade } \\
\text { de Vida no } \\
\text { Trabalho? }\end{array}$} & Folgas & & $X$ & & & & & & \\
\hline & Melhor remuneração & $X$ & & & & & & & \\
\hline & Atendimento padrão & & $X$ & & & & & & \\
\hline & Trabalhar menos horas & & $X$ & & & & & & \\
\hline & Conceder vales/prêmios & $X$ & & & & & & & \\
\hline & $\begin{array}{l}\text { Igualdade entre os } \\
\text { salários }\end{array}$ & $x$ & & & & & & & \\
\hline & $\begin{array}{l}\text { Clareza do escopo de } \\
\text { cada um }\end{array}$ & & $x$ & & & & & & \\
\hline & $\begin{array}{l}\text { Diálogo constante com os } \\
\text { chefes }\end{array}$ & & & & & $X$ & & & \\
\hline & $\begin{array}{l}\text { Maior valorização do } \\
\text { funcionário }\end{array}$ & & & & & $x$ & & & \\
\hline & $\begin{array}{l}\text { Reconhecimento pelo } \\
\text { desempenho }\end{array}$ & & & & & $X$ & & & \\
\hline & $\begin{array}{l}\text { Conceder bonificações } \\
\text { por desempenho }\end{array}$ & $X$ & & & & & & & \\
\hline & $\begin{array}{l}\text { Melhorar o } \\
\text { relacionamento } \\
\text { interpessoal }\end{array}$ & & & & & $X$ & & & \\
\hline
\end{tabular}

Fonte: Elaborado pelos autores (2016).

Analisando o Quadro 6, constata-se que dos questionários respondidos foi possível extrair12 sugestões, as quais foram distribuídas entre 3 das 8 dimensões de Walton. Primeiramente, referente à compensação justa e adequada, o aumento da remuneração, o equilíbrio entre os salários, além da instalação de um sistema que bonificações extras para os funcionários foram temas citados. Para as condições de trabalho, também, foram identificadasas seguintespropostas: sistema de folgas a cada semana, revisão da carga horária, a implementação de um sistema de agendamentos para os serviços ofertados e formalização do escopo de cada funcionário. Em relação ao critério integração social, foram identificadas as seguintes sugestões: melhorar o relacionamento entre o quadro de pessoal, manter contato constante com os funcionários, programa de valorização e reconhecimento do desempenho dos colaboradores. 


\section{CONSIDERAÇÕES FINAIS}

Este estudo buscou analisar a Qualidade de Vida no Trabalho dos colaboradores da X Pet Shop eVeterinária a partir das dimensões de Walton. Por meio do referencial teórico, identificaram-se as principais teorias de QVT e através da teoria de Walton (1973),foram expostos os principais fatores que impactam na QVT. Por meio de um questionário embasado na teoria, foi possível identificar o nível de satisfação dos funcionários, os fatores que de maior relevância na percepção da amostra, além daobtençãodas sugestões dos colaboradores, quanto ao que poderia ser melhorado ou instituído.

Quanto ao nível de satisfação, foi possível verificar que das 35 variáveis estudadas, em 33 delas foram obtidos resultados que indicaram uma avaliação positiva dos funcionários, tendo sido obtido um índice de insatisfação em apenas duas: política de benefícios e incentivo à capacitação. Em relação a primeira, entende-se que a insatisfação está na falta de benefícios extras, não previstos em lei, e à segunda variável relaciona-se o fator de a loja não possuir sistema de auxílio educação.

Dessa forma, a contribuição deste estudo para a organização é percebida pelo levantamento de pontos-chave, através do mapeamento de satisfação em diversas frentes, que devem ser considerados para que se atinja um aumento na Qualidade de Vida no Trabalho dos funcionários.Não obstante os dados do estudo em questão sejam de exclusividade da empresa estudada, os conhecimentos apresentados podem contribuir para outras empresas, conforme o referencial teórico deste estudo.

Também, ainda que o tema Qualidade de Vida no Trabalho forneça dados importantes para a gestão de recursos humanos, bem como salienta Potta (2014), é necessário que sejam expostas as limitações do estudo. É importante considerar que por se tratar de um estudo de caso, voltado a analisar a QVT de uma empresa em específico, de forma que a amostra é limitada, em razão de o número de respondentes ser pequeno, os resultados deste estudo não devem ser generalizados, estando restritos à organização aqui estudada. Ressalta-se que houve um curto espaço de tempo para aplicação do questionário, além desta ter sido remarcada algumas vezes. Também, ainda que tenha sido feita a explicação do conceito de QVT e a pesquisadora tenha ficado disponível para eventuais dúvidas, o fato de que o questionário foi aplicado dentro do espaço físico da loja com tempo estimado para entrega dos envelopes, pode ter inibido a franqueza das respostas.

Por fim, reafirmar a importância do tema desta pesquisa, dado o papel do colaborador na empresa. Tanto os gestores quanto os funcionários devem se favorecer das ações derivadas deste estudo, uma vez que o propósito é proporcionar uma perspectiva de pontos positivos e negativos de QVT, que impactam nos resultados. Em suma, a QVT está relacionada ao equilíbrio entre 
pessoal e profissional, do bem-estar físico ao emocional e sua repercussão impacta diretamente nos resultados que mantém a empresa ativa.

\section{REFERÊNCIAS}

ABVQ - Associação Brasileira de Qualidade de Vida no Trabalho. Qual é o significado de "Qualidade de vida no Trabalho"? Disponível em: <http:/ /www. abqv.com.br/portal/Content.aspx?id=384>. Acesso em: 18 ago. 2015.

ALVES, E. F. Qualidade de vida no trabalho:indicadores e instrumentos de medidas. Disponível em: <http:/ / recil.grupolusofona.pt/bitstream/handle/10437/2983/ Qualidade $\% 20$ de $\% 20$ vida $\% 20$ no $\% 20$ trabalho $\% 20-\% 20$ indicadores $\% 20 \mathrm{e} \% 20$ instrumentos\%20de\%20medidas.pdf?sequence=1 >. Acesso em: 10 set. 2015.

ARAUJO, R. M.; GOMES, F. P.; LOPES, A. O. B. Pesquisa em Administração: qualitativa ou quantitativa? Ano 2011. Disponível em: <http:/ / www.viannajunior. edu.br/files/uploads/20130919_143904.pdf >. Acesso em: 25 out. 2015.

BARROSO, A. L. R. Instrumentos de pesquisa científica qualitativa: vantagens, limitações, fidedignidade e confiabilidade. Revista Digital. 2012. Disponível em: $<$ http:/ / www.efdeportes.com/efd172/instrumentos-de-pesquisa-cientificaqualitativa.htm>. Acesso em: 25 abr. 2016.

CALIXTO, K.O. Qualidade de vida no trabalho: estudo de caso de colaboradores de uma emperesa do setor metalurgico em Queimadas - PB. Ano 2014. Disponível em: <http://dspace.bc.uepb.edu.br/jspui/bitstream/123456789/4581/1/PDF\%20-\%20 Kaline\%20Oliveira\%20Calixto.pdf >. Acesso em: 10 set. 2015.

CHIAVENATO, I. Gestão de Pessoas: e o novo papel dos recursos humanos nas organizações. 2. ed. Rio de Janeiro: Elsevier, 2004.

Gestão de Pessoas: e o novo papel dos recursos humanos nas organizações. 3. ed. Rio de Janeiro: Elsevier, 2010.

COGO, L. Qualidade de vida no trabalho: um diferencial dentro das organizações. Monografia. Universidade do Oeste de Santa Catarina, 2013.

FERRO, F. F. Instrumentos para Medir a Qualidade de Vida no Trabalho e a ESF: uma revisão de literatura. Monografia (Curso de Especialização) - UFMG, Brumadinho, 2012. Disponível em: <https://www.nescon.medicina.ufmg.br/ biblioteca/imagem/3756.pdf $>$.Acesso em:10 set. 2015.

FREITAS, A. L. P; SOUZA, R. G. B. Um modelo para avaliação da Qualidade de Vida no Trabalho em universidades públicas. Disponível em: <http://www.revistasg.uff. br/index.php/sg/article/viewFile/V4N2A4/V4N2A4 >. Acesso em 07 de set. 2015. 
FONSECA, J. J. S. Metodologia da pesquisa científica. Ano: 2002. Disponível em: <http://www.ia.ufrrj.br/ppgea/conteudo/conteudo-2012-1/1SF/Sandra/ apostilaMetodologia.pdf > . Acesso em 25 de Out. 2015.

FOWLER JR, F. J. Pesquisa de levantamento. Porto Alegre: Penso, 2011.

GIL, A. C. Como elaborar projetos de pesquisa. 4. ed. São Paulo: Atlas, 2002.

GOMES, F.; ARAÚJO, R. Pesquisa Quanti-Qualitativa em Administração: uma visão holística do objeto em estudo. Ano 2005. Disponível em: <http:/ / www.ead.fea.usp. $\mathrm{br} /$ semead/8semead/resultado/trabalhosPDF/152.pdf >. Acesso e 25. Out. 2015.

GUEVEL, M. et al. Disabilityandqualityoflifeatwork: anexploratoryresearch in theFrenchpublic sector. Eur. J. Public. Health, v. 25, n. 3, out. 2015.

INSTITUTO BRASILEIRO DE GEOGRAFIA E ESTATÍSTICA - IBGE. < http: / / biblioteca.ibge.gov.br/visualizacao/livros/liv6686.pdf $>$.

JIMENEZ, S. P. B. Qualidade de vida no trabalho. Disponível em: <http:/ / www. portaleducacao.com.br/administracao/artigos/53450/qualidade-de-vida-notrabalho\#!6 > Acesso em 18 ago. 2015.

JUNIOR, S. D. S.; COSTA, F. J. Mensuração e Escalas de Verificação: uma Análise Comparativa das Escalas de Likert e PhraseCompletion. Ano 2014. Disponível em: <http:/ / www.revistapmkt.com.br/Portals/9/Volumes/15/1>. Acesso em 25. de Out. 2015.

LIMONGI-FRANÇA, A. C. Qualidade de Vida no Trabalho - QVT: conceitos e práticas nas empresas da sociedade pós industrial. 2. ed. São Paulo: Atlas, 2012.

MACHAVA, L. I. A. Avaliação da Qualidade de Vida no Trabalho: Um teste empírico do modelo de Walton com enfoque nos Profissionais de Contabilidade da cidade da Beira. Ano 2012. Disponível em: <http:/ / repositorio.ucm.ac.mz/ bitstream/123456789/89/1/Dissertacao-MBA-Lucas-Machava.pdf >. Acesso em 20 de Mai. 2016.

MALHOTRA, N. K. Pesquisa de Marketing: uma orientação aplicada. 6. ed. Porto Alegre: Bookman, 2012.

MARQUES, J. R.QVT - Qualidade de Vida no Trabalho. 2014.Disponível em: <http:/ / www.ibccoaching.com.br/tudo-sobre-coaching/rh-e-gestao-de-pessoas / qualidade-de-vida-no-trabalho-dicas-e-conceitos / >. Acesso em: 16 ago. 2015.

MAY, T. Pesquisa social: questões, métodos e processos. 3. ed. Porto Alegre: Artmed, 2004.

MIRANDA, C. O desafio em manter funcionários motivados: os fatores motivacionais para o trabalho. Escola Superior Aberta do Brasil - ESAB, Vila 
Velha - ES, 2009. Disponível em <http:/ /www.esab.edu.br/wp-content/uploads/ monografias/cely-miranda.pdf $>$. Acesso em 16 de Set. 2015.

MORESI, E. Metodologia da Pesquisa. Ano 2003. Disponível em: <http:/ /www. unisc.br/portal/upload/com_arquivo/metodologia_da_pesquisa.pdf $>$ Acesso em: 25 out. 2015.

MORETTI, S. Qualidade de vida no trabalho X Auto realização humana. Criciúma: Instituto Catarinense de Pós-Graduação, 2007. Disponível em: <http:/ /icpg.com.br/ artigos/rev03-12.pdf > . Acesso em: 19 ago. 2015.

NUNES, M. H. M. Qualidade de Vida no Trabalho: Um estudo com contadores por meio da aplicação do modelo de Hackman e Oldham. Universidade Fumec, 2010. Disponível em <http:/ / www.fumec.br/anexos/cursos/mestrado/dissertacoes / completa/maria-heloisa-de-mendonca-nunes.pdf>. Acesso em: 10 set. 2015.

PEDROSO, B.; PILATTI, L. A,; CANTORANI, J. R. H. Os elementos do projeto de cargo e a qualidade de vida no trabalho: analogia do modelo de Werther e Davis. Disponível em: <http:/ / www.efdeportes.com/efd136/qualidade-de-vida-notrabalho-modelo-de-werther-e-davis.htm>. Acesso em 11 de Set. 2015.

PINHEIRO, M. L. Qualidade de Vida no Trabalho: Um instrumento diferencial nas organizações. Ano 2012. Faculdade Adventista da Bahia. Disponível em 17 de Out. 2015.

POTTA, Gislaine T. R. Qualidade de vida no trabalho como gestão estratégica. Editorial Dom Bosco, 2014. Disponível em: <https:/ /www.domboscoead.com.br/ pos-graduacao/noticias / qualidade-de-vida-no-trabalho-como-gestao-estrategica/28>. Acesso em 30 de Abr. 2016

REQUENA, F. Social Capital, SatisfactionandQualityof Life in theWorkplace. Social IndicatorsResearch, v. 61, n. 3, p. 331-360, mar. 2003.

SANTOS, D. F. A. Qualidade de vida no trabalho: Um estudo sobre a percepção dos funcionários do centro estadual de ensino fundamental Tucunduva. Unijui. Disponível em: < http://bibliodigital.unijui.edu.br:8080/xmlui/bitstream/ handle/123456789/1426/TCC\%20DJENIFER.pdf?sequence=1 >. Acesso em: 08 set. 2015.

SANTOS, E. G.; MATTOS, T. S.; PINTO, R. S. Qualidade de vida no Trabalho diante de um cenário de mudança organizacional: Relato dos servidores do campus Porto - UFPEL. Disponível em: <https:/ / repositorio.ufsc.br/bitstream/ handle/123456789/28938/5.45.pdf?sequence=1>. Acesso em: 15 Set. 2015.

SANTOS, J. A. Qualidade de Vida no Trabalho.X Congresso Nacional de Excelência em Gestão. LATEC/UFF. Disponível em: <http:/ / www.inovarse.org/filebrowser / download/7681>. Acesso em:08 set. 2015. 
SAUER, G. C.; RODRIGUEZ, S. Y. S. Da Qualidade de Vida à Qualidade de Vida no Trabalho: Um Resgate Histórico e Prático. Revista de Psicologia da IMED. 2014. Disponível em: <https:/ / dialnet.unirioja.es/descarga/articulo/5155071.pdf>. Acesso em: 16 ago. 2015.

SILVA, E. L.; MENEZES, E. M. Metodologia da pesquisa e elaboração de dissertação.4. ed. ver. atual. Florianópolis: UFSC, 2005.

SILVA, K. A.; PEDROSO, B.; PILATTI, L. A. Qualidade de vida no trabalho e sociedade pós-moderna: construção de um instrumento de avaliação. 2010. Disponível em: <http:/ / www.fafit.com.br/revista/index.php/fafit/article/ viewFile/13/8>. Acesso em: 07 Set. 2015.

SILVA, M. C.; LIMA, T. B.Análise de fatores que influenciam a Qualidade de Vida no Trabalho de colaboradores de uma organização privada do ramo de segurança na cidade de João Pessoa-PB. Rio de Janeiro: ANPAD, 2011. Disponível em: <http:/ / www.anpad.org.br/diversos/trabalhos/EnGPR/engpr_2011/2011_ENGPR278.pdf >. Acesso em: 18 ago. 2015.

SIRGY, M. J. et al. A New MeasureofQualityofWork Life (QWL)

BasedonNeedSatisfactionandSpilloverTheories. Social IndicatorsResearch, v. 55, n. 3, p. 241-302, set. 2001.

TIMOSSI, L. S.; PEDROSO, B.; PILATTI, L. A.; FRANCISCO, A. C. Adaptação do modelo de Walton para avaliação da qualidade de vida no trabalho. Revista da Educação Física. Maringá, 2009. Disponível em: < http:/ / www.pg.utfpr.edu.br/ ppgep/Ebook/E-book\%202009/2009\%20-\%20PERIODICO/18.pdf >. Acesso em: 08 Set. 2015.

VARGAS, D. O. Qualidade de Vida no Trabalho em uma agência bancária de Porto Alegre. Disponível em: <https:/ / www.lume.ufrgs.br/bitstream/ handle/10183/33325/000789207.pdf?sequence=1>. Acesso em: 21 Out. 2015.

WERTHER, W.; DAVIS, K. Administração de pessoal e recursos humanos. SãoPaulo: McGraw Hill, 1983. 